\title{
The structure of morphological variation in the shape of occlusal surface of permanent teeth in pikas Ochotona (Lagomorpha: Ochotonidae)
}

\begin{abstract}
Valentina R. Volkova \& Andrey A. Lissovsky*
ABSTRACT. Variation in the shape of the occlusal surface of permanent teeth was examined in 102 skulls of four species of pikas. Variance components analysis was carried out on Procrustean coordinates retrieved from 71 and 65 landmarks positioned on the lower and upper teeth rows respectively. The main variance was related to the within-group variation, which indicates general instability in the shape of the enamel loops. Sexual variation explained the smallest amount of variance among all factors examined. The highest percentage of age-related variation was found in the premolars of both teeth rows, especially in $p_{3}$ and $\mathrm{P}^{3}$. The amount of variance due to interspecies variation was relatively low in all analyses, even in the anterior part of $\mathrm{p}_{3}$, which is regularly recommended for the identification of pikas species. There was no evidence of a phylogenetic signal either. Thus we suggest more careful investigation of the role of features of the shape of teeth occlusal surface for species identification.

How to cite this article: Volkova V.R., Lissovsky A.A. 2018. The structure of morphological variation in the shape of occlusal surface of permanent teeth in pikas Ochotona (Lagomorpha: Ochotonidae) // Russian J. Theriol. Vol.17. No.2. P.91-99. doi: 10.15298/rusjtheriol.17.2.05
\end{abstract}

KEY WORDS: Ochotona, Lagomorpha, teeth, geometric morphometrics.

Valentina R.Volkova [volkova.valentina.2014@post.bio.msu.ru], Department of Vertebrate Zoology, Biological Faculty, Lomonosov Moscow State University, Leninskie Gory 1/12, Moscow 119992, Russia; Andrey A. Lissovsky [andlis@zmmu.msu.ru], Zoological Museum of Moscow State University, Bolshaya Nikitskaya 2, Moscow 125009, Russia.

\section{Структура морфологической изменчивости эмалевых петель жевательной поверхности щечных зубов пищух Ochotona (Lagomorpha: Ochotonidae)}

\author{
В.Р. Волкова, А.А. Лисовский*
}

РЕЗЮМЕ. Исследована изменчивость формы жевательной поверхности постоянных щечных зубов 102 черепов, относящихся к четырем современным видам пищух (Lagomorpha: Ochotona). Анализ компонент дисперсии был выполнен на основании прокрустовых координат, полученных в результате анализа 71 и 65 меток, расставленных на зубах нижней и верхней челюстей соответственно. Основная дисперсия была обусловлена внутригрупповой изменчивостью, что отражает общую нестабильность формы эмалевых петель. Половая изменчивость объясняла наименьшую долю дисперсии среди всех изученных факторов. Наибольшая доля возрастной изменчивости была обнаружена в предкоренных зубах, особенно у $\mathrm{p}_{3}$ и $\mathrm{P}^{3}$. Доля межвидовой изменчивости оказалась

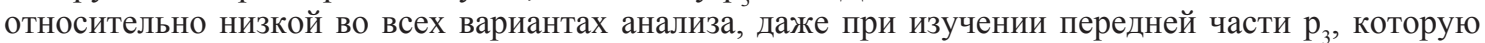
часто рекомендуют для определения видов пищух. Мы не обнаружили филогенетического сигнала в структуре наших данных. В итоге, мы считаем, что необходимо провести более подробное изучение возможной роли признаков формы жевательной поверхности зубов для определения видов пищух.

КЛЮЧЕВЫЕ СЛОВА: Ochotona, Lagomorpha, зубы, геометрическая морфометрия. 


\section{Introduction}

The abundance of pikas (Ochotona Link, 1795) in the Upper Cenozoic sediments of Eurasia makes them a particularly significant element for palaeoecological and biochronological studies (Angelone, 2008). The recent representatives of this genus have a relatively homogenous morphology; in particular, in some cases identification on the basis of external features is complicated or unreliable (Lissovsky, 2014). Most of the fossil remains of these lagomorphs are represented by fragmented skeletons or isolated teeth, which makes their identification even more difficult.

The shape of the occlusal surface, especially of the third lower premolar $\left(\mathrm{p}_{3}\right)$, which is the most variable tooth (Erbajeva, 1988; Čermák et al., 2006; FostowiczFrelik, 2008; Erbajeva, 2016), is the traditional subject of odontological studies in pikas. Some new species' descriptions in palaeontological studies are based on characteristics of this tooth (Erbajeva \& Zheng, 2005). The shape of the third lower premolar, in combination with other odontological and cranial features, has been used for phylogenetic reconstruction of extinct Ochotona (Fostowicz-Frelik et al., 2010).

A detailed description of the Ochotona teeth (Erbajeva, 1988; Sen, 2003; Erbajeva \& Zheng 2005; Čermák et al., 2006; Fostowicz-Frelik, 2008; Čermák \& Rekovets, 2010) has already been published. However, that study was mainly focused on qualitative interspecies differences, while an investigation into the quantitative effects of age variation and a description of individual tooth variation have not yet been conducted.

The main purpose of this work was to investigate the contribution of various factors (sex, age, intraspecies geographical samples, species) to the morphological variation in the shape of the occlusal surface of permanent teeth in pikas, and to determine the value of these odontological features for phylogenetic and taxonomic studies in this group of lagomorphs.

\section{Materials and methods}

We studied the upper and lower permanent cheek teeth in 102 skulls of pikas (Appendix 1) from a craniological collection of the Zoological Museum of Moscow State University (ZMMU, Moscow). The sample was comprised of four species: Ochotona alpina (Pallas, 1773), O. hyperborea (Pallas, 1811), O. macrotis (Günther, 1875), and O. pallasii (Gray, 1867). Species identification was carried out on the basis of cranial and skin colouration features after Lissovsky (2014). The specimens were organized into six geographical groups (sample label first; the number of specimens in parentheses):

O. alpina: Erinat - Russian Federation, Republic of Khakassia, Tashtypskiy District, Erinat river basin (16); Zsayan - Russian Federation, Krasnoyarsk Territory, Yermakovskiy District, Kulumys and Oyskiy Ranges (14) (an additional sample (20) of adult males and females that was not included in the main analysis was studied for sexual variation).

O. hyperborea: Zeyskiy — Russian Federation, Amur Region, Zeyskiy District, Zeyskiy Nature Reserve (14); Barguzin — Russian Federation, Republic of Buryatia, Severo-Baykalskiy District, Barguzin Nature Reserve (13).

O. pallasii: Ulagchin - Mongolia, Bayan-Ölgii Province (10).

O. macrotis: Tianshan - Kyrgyzstan and Kazakhstan, Terskey Ala-Too Range (15).

Each sample contained six sex and age groups: juvenile, subadult and adult males and the same categories of females. The sex of animals was recorded on the museum label. The age of the pikas was determined by evaluating the condition of the crests of the lower jaw and the general shape of the skull (Lissovsky, 2004). Unfortunately, the sample size was limited since juvenile pikas with permanent dentition are rare in museum collections around the world.

The objects of our study were represented by twodimensional projections of permanent teeth rows on the right side of the lower and upper jaws from the occlusal (chewing) surface. If the right side lacked dentition, we reflected the left dentition vertically in the graphic editor. Photos of the tooth surfaces were taken using an Olympus SZX10 binocular microscope and a DeltaPix Invenio II camera (magnification x12.5). The axial skull and lower jaw were fixed in place using plasticine as follows: the dental row was manually positioned so that the buccal side of the right dentition was perpendicular to the focal plane of the lens. To minimize any error in positioning the dentition, three sets of photos were taken, each time reinstalling the jaw on the microscope stage (Polly, 2001). The chewing surface of the tooth is a three-dimensional object; therefore at high magnification we encountered a problem with the lack of focus depth. To obtain images with the required depth of focus, we applied the method of stacking by focus using the Helicon Focus software (v. 6.7.1). This software aligns several focused parts of the same object from several photographs in one sharp picture. Thus, we combined three pictures focused at different heights of the tooth crown.

We studied the configuration of 71 landmarks for the lower tooth row (Fig. 1A), distributed as follows: $p_{3}$ -22 landmarks, $\mathrm{p}_{4}-13, \mathrm{~m}_{1}-15, \mathrm{~m}_{2}-15, \mathrm{~m}_{3}-6$. For the upper teeth we used 65 landmarks (Fig. 1B): $\mathrm{P}^{2}$ $-6, \mathrm{P}^{3}-16, \mathrm{P}^{4}-14, \mathrm{M}^{1}-14, \mathrm{M}^{2}-15$. The landmarks were located on the images of the teeth using a screen digitizer TPSdig v.1.40 (Rohlf, 2004). Each landmark had $\mathrm{X}$ and $\mathrm{Y}$ coordinates in the orthogonal system, reflecting its position on the picture. Thus, the 142 and 130 variables characterizing the position of landmarks on the upper and lower jaws in the Cartesian system were used as primary data in the quantitative analysis.

All the quantitative analyses were carried out using each tooth separately. To obtain the variables of shape 


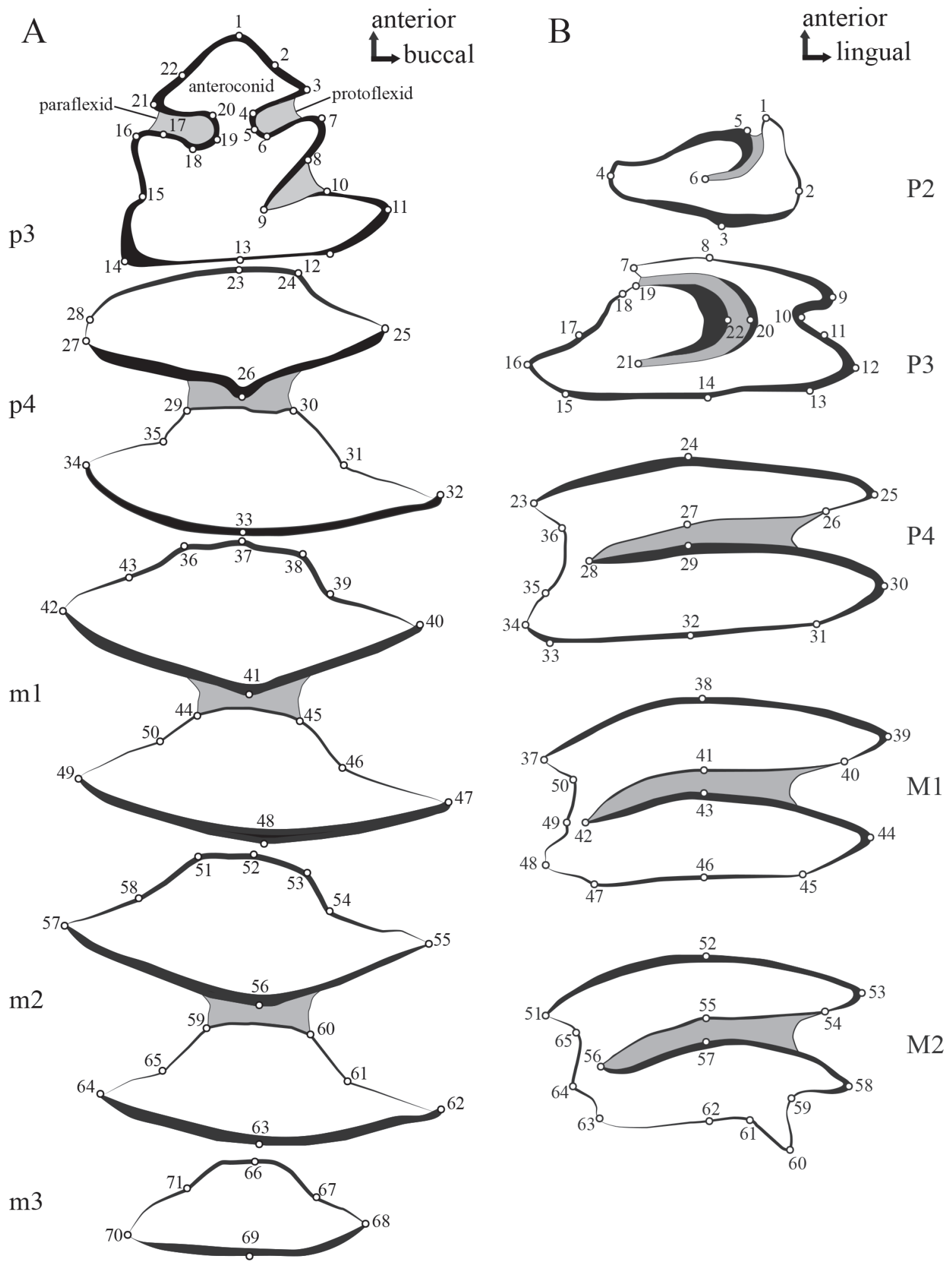

Fig. 1. Location of landmarks used in the analysis. A - lower tooth row; B - upper tooth row. 
that are independent of the position of the tooth on the picture (Procrustean coordinates, PrC), the landmark configurations were aligned using the principal axes option of the MorphoJ software (Klingenberg, 2011). The PrC were not normalized.

We investigated five factors that can affect the variation in morphological structures or their description: errors in tooth positioning when taking photos and/or landmark positioning during digitization, sex (SEX), age (AGE), and two kinds of taxonomic indicators. The first, namely sample (SAM), contains the identifier of a single-species geographic sample; it can be considered as a generalized factor of taxonomic variation when several species are being analysed. The second, species (SPE), contains the species ID, and thus does not consider intra-species variation.

We used Wilks' criterion to evaluate differences between three repeats of tooth positioning. Other analyses used one of the MANOVA variants, namely the maximum likelihood algorithm of the variance components analysis (after Lissovsky \& Pavlinov, 2008), in order to estimate the percentage variance associated with various factors. Factors (SEX, AGE, etc.) were considered as non-fixed factors, and the PrC of each tooth separately as dependent variables. The contribution $\left(S_{j}\right)$ of each factor $(j)$ to the total diversity of all variables (i) was calculated using the formula:

$$
S_{j}=\frac{\sum_{i=1}^{\mathrm{K}} \mathrm{S}_{\mathrm{ij}}}{\sum_{\mathrm{j}=1}^{\mathrm{K}} \sum_{\mathrm{i}=1}^{\mathrm{C}} \mathrm{S}_{\mathrm{ij}}}
$$

where $s_{i j}$ - the proportion of variance for one $\operatorname{PrC}(\mathrm{i})$ for each factor or the within-group variation, $\mathrm{C}-$ the number of $\mathrm{PrC}, \mathrm{K}$ - the number of factors plus 1 (for within-group variation).

The ranges of the variance components were estimated using a subsampling approach. We generated 100 replicas by randomly removing one element from each age/sample group (or sex/sample in the case of sexual variation analysis). The fixed rate of removal was due to the small sample size. We could not use bootstrap techniques in our case, because specimens return (causing duplicated specimens) produces regular variance bias by reducing intrasample variation.

As in any version of MANOVA, the results depend on the design of the analysis. We assumed that age and sex variation could be sample-specific (Thorpe, 1976), so we used a nested design (SEX and AGE are nested in SAM, SAM is nested in SPE).

The analysis was carried out in several steps. In the first step, we calculated the amount of variance explained by the error in the positioning of the teeth under the microscope and the arrangement of the landmarks. In subsequent analyses we used the average configuration from three repeats.

In the second step, we estimated sexual variation. Since samples containing both genders of all ages are rare in museum collections, we conducted two different analyses. In the first case, we calculated the percentage of variance explained by sexual variation in a sample of adults of one species from one place (Zsayan sample with an equal ratio of males:females $=10: 10)$. In the second case, we estimated the percentage of variance in a set of adults from six geographical samples with an equal sex ratio: Barguzin ( 2 males: 2 females), Erinat (4:4), Tianshan (3:3), Ulagchin (2:2), Zeyskiy (2:2), Zsayan (3:3). The design for this analysis included two factors (SEX and SAM, SEX is nested in SAM). Since the results of this step revealed only a small amount of sexual variation, we did not consider it in subsequent analyses.

In the third step, we considered three factors: SPE, SAM and AGE. The following three design options were used: (1) all six samples (factors: AGE and SAM, AGE is nested in SAM); (2) O. alpina and O. hyperborea only, each species represented by two samples (factors: AGE and SAM, AGE is nested in SAM); (3) $O$. alpina and $O$. hyperborea only (factors: AGE, SAM, and SPE; AGE is nested in SAM, SAM is nested in SPE).

The following analysis was carried out in order to provide a rough estimate of the phylogenetic signal in our data. We analysed three pairs of species: alpina + hyperborea, alpina + macrotis and alpina + pallasii; factors: AGE and SPE, AGE is nested in SPE. The percentages of variance of interspecies differences in different pairs of species were compared later.

As we found that interspecies differences were relatively small, we looked for the parts of the third lower premolar $\left(\mathrm{p}_{3}\right)$ that displayed the most interspecies variation. In order to perform this search, we estimated the amount of interspecific variance (factors: AGE and SPE, AGE is nested in SPE) for each of the variables and selected all variables for which the ratio of the partial interspecies variance $s_{i j}$ to the total interspecies variance $S_{j}$ was greater than the same indicator for the within-group variance. The landmarks corresponding to such variables are shown in the figure 2 . The analysis was carried out on the same three pairs of species.

Additionally we evaluated the option of using the most popular element of the dental system for species' identification in pikas: the shape of the anteroconid and two anterior reentrant folds (para- and protoflexid) of $\mathrm{p}_{3}$. The percentage of interspecific variance was calculated for 14 landmarks (1-7th and 16-22th) (factors: AGE and SPE, AGE is nested in the SPE).

We used the Statistica software package (version 13.0) for all calculations, mainly the Variance Components module. Original algorithms were written by A.A. Lissovsky using Statistica Visual Basic language.

\section{Results}

Analysis of teeth positioning error and landmark positioning error

We found no differences between the $\operatorname{PrC}$ of the three repeats (for the lower row: $\lambda=0.5, F=0.6, p=$ 
Table 1. Variance proportion (\%) of intersample (SAM), sexual (SEX) and withingroup (Error) variation in all samples of pika teeth from adult specimens (SEX is nested in SAM; variation range in parentheses).

\begin{tabular}{|c|c|c|c|}
\hline \multirow{2}{*}{ Tooth } & \multicolumn{3}{|c|}{ Form of variability } \\
\cline { 2 - 4 } & SAM & SEX & Error \\
\hline $\mathrm{p}_{3}$ & $33.5(27.4-42.7)$ & $0.7(0.2-3.2)$ & $65.8(55.2-69.9)$ \\
\hline $\mathrm{p}_{4}$ & $28.7(20.2-37.9$ & $1.5(0.2-4.4)$ & $69.8(60.4-77.4)$ \\
\hline $\mathrm{m}_{1}$ & $31.8(22.0-46.3)$ & $2.7(0.9-9.3)$ & $65.5(50.0-74.2)$ \\
\hline $\mathrm{m}_{2}$ & $28.6(20.8-39.4)$ & $1.1(0.0-8.3)$ & $70.4(57.3-77.8)$ \\
\hline $\mathrm{m}_{3}$ & $17.1(13.0-38.8)$ & $0.0(0.0-3.1)$ & $82.9(61.1-86.9)$ \\
\hline $\mathrm{P}^{2}$ & $16.5(7.3-39.8)$ & $0.0(0.0-4.0)$ & $83.5(60.0-92.7)$ \\
\hline $\mathrm{P}^{3}$ & $25.2(12.7-38.0)$ & $1.5(0.2-13.9)$ & $73.2(59.3-86.8)$ \\
\hline $\mathrm{P}^{4}$ & $24.0(13.7-36.8)$ & $0.1(0.0-5.4)$ & $75.8(62.8-85.4)$ \\
\hline $\mathrm{M}^{1}$ & $23.5(11.9-38.1)$ & $0.9(0.0-5.3)$ & $75.6(61.2-87.8)$ \\
\hline $\mathrm{M}^{2}$ & $14.8(10.3-33.5)$ & $0.4(0.0-4.9)$ & $84.8(62.5-89.4)$ \\
\hline
\end{tabular}

Table 2. Variance proportion (\%) of sexual (SEX) and within-group (Error) variation of adult pika teeth from

Zsayan sample (variation range in parentheses).

\begin{tabular}{|c|c|c|}
\hline \multirow{2}{*}{ Tooth } & \multicolumn{2}{|c|}{ Form of variability } \\
\cline { 2 - 3 } & SEX & Error \\
\hline $\mathrm{p}_{3}$ & $1.7(0.8-4.0)$ & $98.3(96.0-99.1)$ \\
\hline $\mathrm{p}_{4}$ & $3.2(1.4-7.0)$ & $96.8(93.0-98.6)$ \\
\hline $\mathrm{m}_{1}$ & $0.7(0.2-3.2)$ & $99.3(96.8-99.8)$ \\
\hline $\mathrm{m}_{2}$ & $0.4(0.0-3.4)$ & $99.6(96.6-100.0)$ \\
\hline $\mathrm{m}_{3}$ & $0.0(0.0-3.4)$ & $100(96.6-100.0)$ \\
\hline $\mathrm{P}^{2}$ & $0.0(0.0-1.9)$ & $100(98.0-100.0)$ \\
\hline $\mathrm{P}^{3}$ & $2.1(0.7-4.1)$ & $97.9(95.9-99.3)$ \\
\hline $\mathrm{P}^{4}$ & $4.6(2.3-9.2)$ & $95.4(90.8-97.7)$ \\
\hline $\mathrm{M}^{1}$ & $2.2(0.7-4.2)$ & $97.8(95.8-99.3)$ \\
\hline $\mathrm{M}^{2}$ & $1.4(0.2-3.5)$ & $98.6(96.5-99.9)$ \\
\hline
\end{tabular}

1.000; for the upper teeth row: $\lambda=0.6, F=1, p=$ $1.000)$. The percentage of variance linked with this kind of error for different teeth lay in the range of 0.0 $2.0 \%$.

\section{Sexual variation}

Sexual dimorphism in both the lower and upper teeth of pikas was weak (Tab. 1): the percentage variance did not exceed $2.7 \%$, with the range varying between 0 and $14 \%$ in different teeth, mainly below $6 \%$.

In the analysis of 20 adult Zsayan individuals, sexual dimorphism in both the lower and upper teeth was also weak (Tab. 2): the percentage variance did not exceed $4.6 \%$, with the range varying between 0 and $10 \%$, mainly below $4 \%$.
Taxonomic and age-related variation

Comparison of intersample and age-related variation - Within-group variance was notably dominant in the general variation of tooth shape in six pika samples, accounting for more than half of the total diversity (Tab. 3). The percentages of sample- and age-related variation were similar, falling roughly within $2-20 \%$. The maximum intersample variation was $22.8 \%$, while that of age variation was $26.2 \%$.

The maximum age-related variance occurred in the third lower $\left(\mathrm{p}_{3}\right)$ and third upper $\left(\mathrm{P}^{3}\right)$ premolars, and the minimum in the third lower $\left(\mathrm{m}_{3}\right)$ and first upper $\left(\mathrm{M}^{1}\right)$ molars. The $\mathrm{m}_{1}$ showed the maximum intersample variation; $p_{3}$ took sixth place according to this analysis. The results of the analysis of four samples of alpina + hyperborea (Tab. 3) were similar to the pattern described above.

When the SPE factor was added to the analysis of alpina + hyperborea (Tab. 4), the amount of age-related and within-group variation remained similar, while the intersample variance was divided between two factors: SAM and SPE. The percentage of interspecies variance was no greater than the intersample variance (except for $\mathrm{m}_{3}$, in which the species-related variation was greater, but $95 \%$ of the whole variation remained unexplained). In the case of $\mathrm{m}_{2}$ and all upper teeth except for $\mathrm{P}^{2}$ the intersample variation range did not intersect the interspecies variation range.

Species-related variation - The interspecies variance in the three pairs of species was also small (Tab. $5)$. We did not find any "universal teeth" for species identification. The landmarks of $\mathrm{p}_{3}$, most "loaded" by interspecific differences, are shown in Fig. 2. The pattern of interspecies differences was specific for each 
Table 3. Variance proportion (\%) of intersample (SAM), age-related (AGE) and within-group (Error) variation in pika teeth (AGE is nested in SAM; variation range in parentheses).

\begin{tabular}{|c|c|c|c|c|c|c|}
\hline \multirow{2}{*}{ Tooth } & \multicolumn{3}{|c|}{ all samples } & \multicolumn{3}{c|}{ alpina + hyperborea } \\
\cline { 2 - 7 } & SAM & AGE & Error & SAM & AGE & Error \\
\hline \multirow{2}{*}{$\mathrm{p}_{3}$} & 11.5 & 21.6 & 66.9 & 7.9 & 22.2 & 69.9 \\
& $(9.3-13.7)$ & $(16.6-26.2)$ & $(62.8-71.7)$ & $(6.4-10.4)$ & $(17.2-27.5)$ & $(64.5-74.4)$ \\
\hline \multirow{2}{*}{$\mathrm{p}_{4}$} & 13.4 & 7.3 & 79.3 & 10.9 & 7.3 & 81.7 \\
& $(9.9-18.6)$ & $(4.9-11.2)$ & $(73.6-84.4)$ & $(6.7-15.6)$ & $(5.0-12.5)$ & $(75.3-86.8)$ \\
\hline \multirow{2}{*}{$\mathrm{m}_{1}$} & 18.3 & 8.9 & 72.8 & 11.1 & 10.5 & 78.4 \\
& $(15.8-22.8)$ & $(5.7-12.1)$ & $(66.4-77.5)$ & $(6.3-15.2)$ & $(6.2-14.1)$ & $(72.0-83.9)$ \\
\hline \multirow{2}{*}{$\mathrm{m}_{2}$} & 16.9 & 9.4 & 73.7 & 9.2 & 11.2 & 79.6 \\
& $(13.7-20.3)$ & $(6.9-13.2)$ & $(67.6-79.0)$ & $(6.4-14.1)$ & $(8.4-14.4)$ & $(73.6-83.9)$ \\
\hline \multirow{2}{*}{$\mathrm{m}_{3}$} & 4.6 & 2.2 & 93.2 & 2.2 & 2.5 & 95.3 \\
& $(2.4-7.6)$ & $(0.4-4.7)$ & $(88.6-95.6)$ & $(0.3-4.8)$ & $(1.1-5.6)$ & $(91.7-97.7)$ \\
\hline \multirow{2}{*}{$\mathrm{P}^{2}$} & 8.9 & 10.5 & 80.6 & 6.4 & 8.3 & 85.3 \\
& $(5.9-12.9)$ & $(7.7-15.6)$ & $(75.0-85.3)$ & $(3.8-10.8)$ & $(5.2-13.4)$ & $(79.1-89.7)$ \\
\hline \multirow{2}{*}{$\mathrm{P}^{3}$} & 14.7 & 14.5 & 70.7 & 7.2 & 17.2 & 75.6 \\
& $(11.8-16.9)$ & $(11.7-18.1)$ & $(66.0-74.1)$ & $(5.2-10.3)$ & $(14.4-21.0)$ & $(70.3-80.4)$ \\
\hline \multirow{2}{*}{$\mathrm{P}^{4}$} & 9.3 & 9.8 & 81.0 & 9.2 & 8.2 & 82.5 \\
& $(6.7-11.0)$ & $(6.4-13.0)$ & $(76.1-85.1)$ & $(6.9-11.6)$ & $(4.9-11.5)$ & $(77.5-86.6)$ \\
\hline \multirow{2}{*}{$\mathrm{M}^{1}$} & 10.8 & 1.9 & 87.3 & 8.6 & 2.1 & 89.3 \\
& $(8.1-16.2)$ & $(1.2-3.2)$ & $(80.9-89.8)$ & $(5.6-14.6)$ & $(1.4-4.8)$ & $(82.5-92.6)$ \\
\hline \multirow{2}{*}{$\mathrm{M}^{2}$} & 14.2 & 4.0 & 81.9 & 10.8 & 5.4 & 83.7 \\
& $(10.3-17.3)$ & $(1.8-6.4)$ & $(78.4-87.0)$ & $(7.6-15.2)$ & $(3.6-9.4)$ & $(77.8-88.1)$ \\
\hline
\end{tabular}

Table 4. Variance proportion (\%) of species-related (SPE), intersample (SAM), age-related (AGE) and within-group (Error) variation in pika teeth of alpina + hyperborea sample (AGE is nested in SAM, SAM is nested in SPE; variation range in parentheses).

\begin{tabular}{|c|c|c|c|c|}
\hline Tooth & SPE & SAM & AGE & Error \\
\hline $\mathrm{p}_{3}$ & $4.8(3.3-7.5)$ & $3.7(1.7-6.1)$ & $22.5(18.4-27.8)$ & $69.0(63.1-73.8)$ \\
\hline $\mathrm{p}_{4}$ & $4.8(2.7-7.4)$ & $6.8(3.2-9.8)$ & $7.6(5.1-11.8)$ & $80.7(74.8-86.8)$ \\
\hline $\mathrm{m}_{1}$ & $3.3(2.0-4.9)$ & $8.1(4.6-11.5)$ & $10.8(6.8-14.6)$ & $77.7(72.0-85.6)$ \\
\hline $\mathrm{m}_{2}$ & $2.1(0.8-3.9)$ & $7.3(4.5-10.8)$ & $11.4(8.3-15.3)$ & $79.3(74.7-83.6)$ \\
\hline $\mathrm{m}_{3}$ & $2.8(1.1-4.6)$ & $0.0(0.0-1.7)$ & $2.5(1.1-6.0)$ & $94.7(89.1-97.0)$ \\
\hline $\mathrm{P}^{2}$ & $4.0(1.2-8.9)$ & $2.6(0.3-6.0)$ & $8.4(6.0-12.3)$ & $85.0(80.5-89.3)$ \\
\hline $\mathrm{P}^{3}$ & $1.5(0.7-3.1)$ & $6.0(3.5-8.3)$ & $17.4(14.8-22.6)$ & $75.0(68.7-79.0)$ \\
\hline $\mathrm{P}^{4}$ & $2.2(1.1-4.4)$ & $7.2(4.8-9.3)$ & $8.3(5.6-11.9)$ & $82.3(78.0-86.3)$ \\
\hline $\mathrm{M}^{1}$ & $1.7(0.5-3.1)$ & $7.1(4.0-12.7)$ & $2.3(1.2-4.3)$ & $89.0(81.0-92.0)$ \\
\hline $\mathrm{M}^{2}$ & $2.0(0.9-3.4)$ & $9.1(5.8-12.9)$ & $5.6(3.5-8.8)$ & $83.3(79.2-86.9)$ \\
\hline
\end{tabular}

pair of species; only landmarks 4, 6 and 10 contributed to the separation of all three pairs. The study of the anteroconid and two anterior folds of $p_{3}$ produced results similar to those described above (Tab. 6). The ranges of values of interspecies-related variance in the three pairs of species intersected widely.

\section{Discussion}

Our analysis of specimens of known species and gender allowed us to re-evaluate the significance of some of the odontological features used for pikas identification. We did not consider tooth size or the struc- ture of enamel, and our conclusions concern only the shape of the enamel loops of the occlusal surface, which is most often used in tooth identification. Moreover, our results are dependent on specific landmark scheme and thus should be considered as preliminary.

We found that the teeth positioning error did not cause systematic error, so in principle, pika teeth can be studied successfully by geometric morphometry methods. However, the very high proportion of within-group variation in all analyses indicated general instability in the shape of the enamel loops, which was not related to the factors considered by us. Commonly, such variation, which cannot be explained by a known set of 


\begin{tabular}{|c|c|c|c|c|c|c|c|c|c|c|c|}
\hline \multirow{3}{*}{ 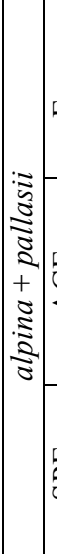 } & & 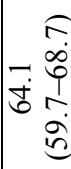 & 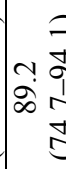 & 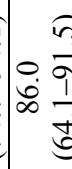 & 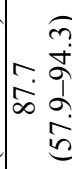 & 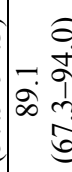 & 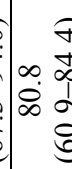 & $\hat{5}$ & 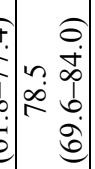 & $\begin{array}{cc} & \sigma \\
\sigma & \overline{1} \\
\infty & \overline{1} \\
\infty & \sim \\
& \infty \\
& 0\end{array}$ & 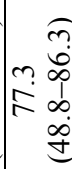 \\
\hline & 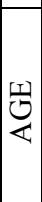 & 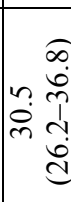 & 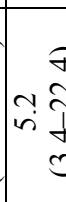 & $\begin{array}{ll} & 7 \\
+ & 0 \\
\infty & 1 \\
0 & 0\end{array}$ & $\begin{array}{ll} & 0 \\
& 0 \\
0 & \stackrel{+}{+} \\
\infty & 0 \\
& 0 \\
& 0\end{array}$ & 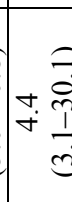 & 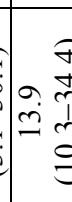 & 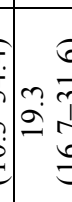 & 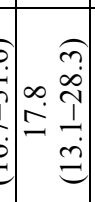 & 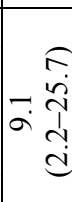 & $\begin{array}{ll}1 \\
0 \\
\infty & 5 \\
& 5 \\
& 5\end{array}$ \\
\hline & $\stackrel{\vec{d}}{\vec{n}}$ & 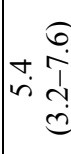 & $\begin{array}{l}0 \\
07 \\
i \frac{1}{1} \\
=\end{array}$ & $\begin{array}{ll} & 0 \\
0 & \infty \\
ن & 1 \\
& 0\end{array}$ & $\begin{array}{ll} & 0 \\
0 & \infty \\
+ & 1 \\
& 0 \\
0\end{array}$ & $\underset{0}{+\frac{\infty}{1}}$ & 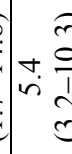 & $?$ & $\hat{f}$ & $\begin{array}{r}\frac{n}{0} \\
-\frac{1}{1} \\
\frac{a}{j}\end{array}$ & $\exists$ \\
\hline \multirow{3}{*}{ 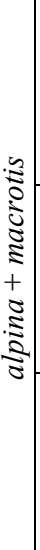 } & $\underset{\text { ț }}{\stackrel{5}{ \pm}}$ & 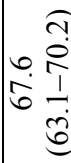 & $\begin{array}{ll}0 & 7 \\
0 & \overline{0} \\
\infty & 1 \\
0 & 0\end{array}$ & $\mid \begin{array}{ll}\infty \\
\infty & \frac{\infty}{\infty} \\
\infty & \frac{1}{2}\end{array}$ & 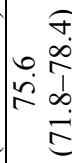 & 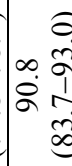 & 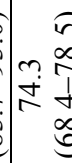 & 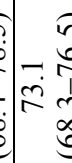 & 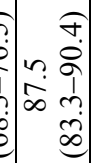 & 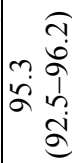 & $\begin{array}{l}0 \\
0 \\
\infty \\
\infty \\
0\end{array}$ \\
\hline & & 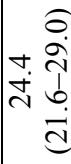 & $\begin{array}{r}7 \\
-7 \\
7 \\
7\end{array}$ & {$\left[\begin{array}{r}2 \\
-\frac{1}{1} \\
0 \\
0\end{array}\right.$} & $\begin{array}{r}0 \\
-\frac{0}{7} \\
0 \\
0 \\
0\end{array}$ & $\begin{array}{r}\pi \\
=\pi \\
=\end{array}$ & 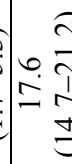 & 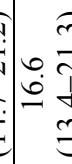 & 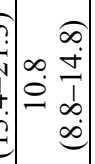 & $\begin{aligned} & 0 \\
& \vec{\sim} \stackrel{f}{+} \\
& \stackrel{f}{\Xi}\end{aligned}$ & $\stackrel{0}{\circ}$ \\
\hline & $\frac{1}{\tilde{\omega}}$ & 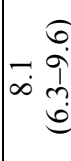 & 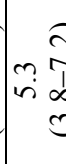 & $\begin{array}{l}n \\
= \\
= \\
0\end{array}$ & 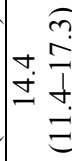 & $-\frac{7}{7}$ & $\begin{array}{r}\frac{1}{1} \\
-\frac{1}{\infty} \\
0\end{array}$ & $\hat{\imath}$ & 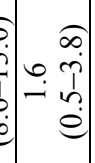 & 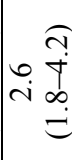 & $\underset{\sim}{\infty}$ \\
\hline & 矛 & $\begin{array}{c}\frac{\pi}{\pi} \\
\cdots \\
\frac{\pi}{\sigma} \\
\hat{\sigma}\end{array}$ & $\begin{array}{cc} & 7 \\
1 & 2 \\
1 & 0 \\
\infty & 0 \\
0 & 0\end{array}$ & 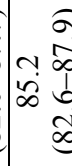 & 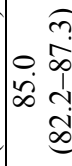 & 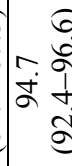 & $\mid \begin{array}{ll} & 0 \\
r & \infty \\
\infty & \infty \\
\infty & \frac{1}{2} \\
& \alpha\end{array}$ & 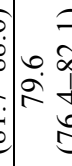 & 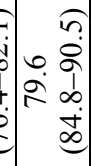 & 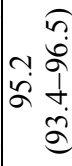 & 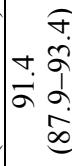 \\
\hline & 민 & 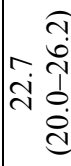 & $\frac{6}{\infty}$ & {$\left[\begin{array}{l}7 \\
0 \\
0 \\
0 \\
1 \\
1\end{array}\right.$} & 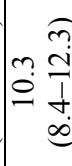 & $\stackrel{7}{\pi}$ & 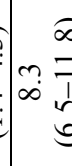 & 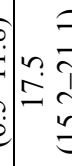 & 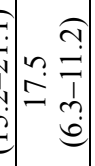 & 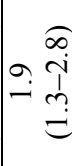 & $\stackrel{\infty}{\forall}$ \\
\hline & $\frac{w}{2}$ & $\begin{array}{cc} & 7 \\
0 & \pi \\
0 & 0 \\
0 & 0\end{array}$ & $\begin{array}{r}1 \\
0 \\
0 \\
0 \\
0 \\
0\end{array}$ & $\mid \begin{array}{ll} & 0 \\
\infty & 0 \\
\dot{+} & 0 \\
& 0\end{array}$ & 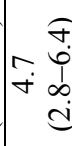 & $\begin{array}{ll} & 0 \\
\infty & + \\
i & + \\
& \end{array}$ & $\mid \begin{array}{ll} & 2 \\
0 & 7 \\
i & 1 \\
& 0\end{array}$ & 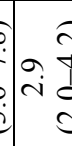 & 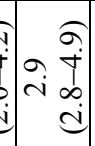 & 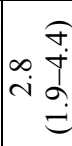 & $\infty$ \\
\hline & & $\tilde{2}$ & 2 & $\Xi$ & $\Xi$ & $\Xi$ & $\theta$ & 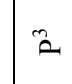 & o & $\Sigma$ & 2 \\
\hline
\end{tabular}

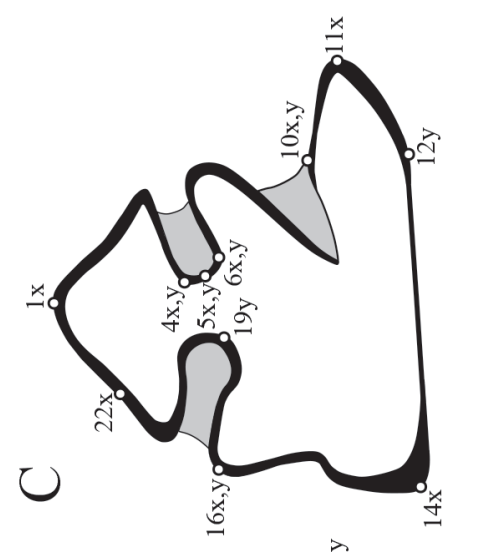

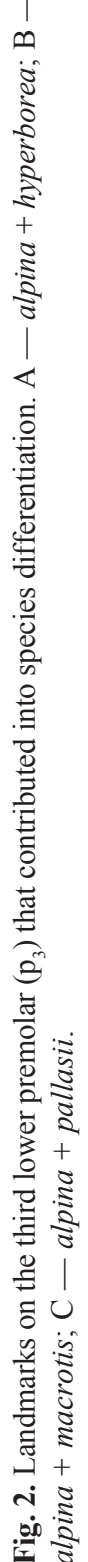

factors, is referred to as individual variation, implying that it originates from the individual peculiarities of ontogenesis rather than being influenced by regular external or internal factors. Whatever the reasons for the high within-group variation in our study, this variation would negatively affect the possibility of species identification using any detached tooth.

According to the results of our analysis, sexual variation explained the smallest amount of variance among all factors examined. The absence of sexual dimorphism of craniometric features in pikas has been reported previously (Lissovsky, 2014). Age-related variation is more important. Within both tooth rows, the highest percentage of this variation was found in the premolars (especially in $\mathrm{p}_{3}$ and $\mathrm{P}^{3}$ ). This phenomenon can easily be explained, since different stages of tooth wearing from a conical to permanent prismatic form can be found in this kind of tooth (molars have a more or less prismatic shape in the age ranges available in museum collections). The process of wearing out was 
Table 6. Variance proportion (\%) of species-related (SPE), age-related (AGE) and within-group (Error) variation in anterior part of pika $p_{3}$ for different samples (AGE is nested in SPE; variation range in parentheses).

\begin{tabular}{|c|c|c|c|}
\hline Sample & SPE & AGE & Error \\
\hline alpina + hyperborea & $6.2(4.9-7.5)$ & $22.8(20.2-26.7)$ & $71.0(67.6-73.6)$ \\
\hline alpina + macrotis & $5.8(4.0-8.1)$ & $23.7(21.0-27.5)$ & $70.4(65.9-74.2)$ \\
\hline alpina + pallasii & $6.5(3.2-7.9)$ & $28.7(25.8-39.2)$ & $64.8(56.5-69.3)$ \\
\hline
\end{tabular}

partly described earlier in $\mathrm{p}_{3}$ (Lissovsky \& Serdyuk, 2004; Lissovsky, 2004).

The proportion of variance linked with taxonomic variation was relatively low in all variants of analysis (Tabs 1, 3, 4), including pairwise species comparison and a combined sample of four species. The wide overlapping values of intra- and interspecies variation in the alpina + hyperborea sample (Tab. 4) indicate that the difference between species does not exceed intraspecies variation. Even in the case of the anterior part of $\mathrm{p}_{3}$, which is regularly recommended for the identification of pikas species (Erbajeva, 1988; Gromov \& Erbajeva, $1995)$, the percentage of interspecific variance did not exceed $8 \%$. In addition, the leading role of $\mathrm{p}_{3}$ for species identification is not supported by our results.

Although our study did not directly consider the identification of pikas on the basis of teeth shape features, the predominance of within-sample variation over the taxonomic variation indicates that it would be difficult to find stable diagnostic features in small samples of detached teeth, which are the common subject of palaeontological studies. Undoubtedly, the possibility of species identification should be further investigated on the basis of a larger sample that would allow us to estimate the actual overlap in the morphological features between different pairs of species.

We analysed three pairs of species that represent various levels of phylogenetic affinity. Ochotona alpi$n a$ and $O$. hyperborea are closely related species, and representatives of sister species groups (Lissovsky et al., 2007; Lissovsky, 2014). O. alpina and O. pallasii belong to one subgenus, namely Pika Lácèpde, 1799, although they are not closely related (Lissovsky, 2014; Lissovsky et al., 2016). Ochotona macrotis is a member of another subgenus, Conothoa Lyon, 1904, and is phylogenetically distant from the other three species (Yu et al., 2000; Lissovsky, 2014). Thus in the presence of a clearly expressed phylogenetic signal, the proportion of interspecies variance should increase in the direction: alpina + hyperborea alpina + pallasii; alpina + macrotis. No such pattern was observed in the current study (Tab. 6), which points to a weak phylogenetic signal in our dataset. Of course, this result is also preliminary and final conclusions on the significance of teeth shape features for phylogenetic signal searching should be made on the basis of a larger sample. However, our study highlights that determining the phylogenetic relationships of pikas on the basis of the shape of tooth enamel loops could be problematic.
Acknowledgements. We would like to thank Leonid L. Voyta (St. Petersburg) for discussion of different steps of this study; Petr P. Dmitriev (Moscow) gave a number of valuable comments during the paper preparation. Stanislav Čermák (Prague) and Chiara Angelone (Roma) helped us to improve this paper notably.

This study supported by the Russian Foundation for Basic Research, Grant 18-04-00369; and research project of MSU Zoological Museum (AAAA-A16116021660077-3).

\section{References}

Angelone C. 2008. Family Ochotonidae (Lagomorpha) and its application in biochronology: some case studies from the Plio-Quaternary of Eurasia // Quaternary International. Vol.179. No.1. P.5-8.

Čermák S., Obuch J. \& Benda P. 2006. Notes on the genus Ochotona in the Middle East (Lagomorpha: Ochotonidae) // Lynx (Praha). Vol.37. P.51-66.

Čermák S. \& Rekovets L.I. 2010. Early Pliocene ochotonids (Mammalia, Lagomorpha) from Southern Ukraine// Geodiversitas. Vol.32. No.1. P. 107-120.

Erbajeva M.A. 1988. [Pikas of Cenozoic]. Moscow: Nauka. 222 p. [In Russian]

Erbajeva M.A. 2016. The ochotonids of Eurasia: Biochronology and taxonomic diversity // Biology Bulletin. Vol.43. No.7. P.729-735.

Erbajeva M.A. \& Zheng S. 2005. New data on late MiocenePleistocene ochotonids (Ochotonidae, Lagomorpha) from North China // Acta Zoologica Cracoviensia. Vol.48. No.1-2. P.93-117.

Fostowicz-Frelik Ł. 2008. Review of the earliest Central European Ochotona (Mammalia: Lagomorpha), with a description of a new species from Poland // Mammalia. Vol.72. No.2. P.71-81.

Fostowicz-Frelik Ł., Frelik G.J. \& Gasparik M. 2010. Morphological phylogeny of pikas (Lagomorpha: Ochoto$n a$ ), with a description of a new species from the Pliocene/ Pleistocene transition of Hungary // Proceedings of the Academy of Natural Sciences of Philadelphia. Vol.159. No.1. P.97-118.

Gromov I.M. \& Erbajeva M.A. 1995. [The Mammals of Russia and adjacent territories Lagomorphs and Rodents]. St. Petersburg: Zoological Institute of Russian Academy of Sciences. 520 p. [In Russian]

Klingenberg C.P. 2011. MorphoJ: an integrated software package for geometric morphometrics: Computer Program Note // Molecular Ecology Resources. Vol.11. No.2. P.353-357. 
Lissovsky A.A. 2004. Contribution to age determination of pikas (Lagomorpha, Ochotonidae, Ochotona) // Russian Journal of Theriology. Vol.3. No.1. P.43-48.

Lissovsky A.A. 2014. Taxonomic revision of pikas Ochoto$n a$ (Lagomorpha, Mammalia) at the species level // Mammalia. Vol.78. No.2. P.199-216.

Lissovsky A.A. \& Serdyuk N.V. 2004. Identification of late Pleistocene pikas (Ochotona, Lagomorpha, Mammalia) of the alpina-hyperborea group from Denisova Cave (Altai) on the basis of the anterior lower premolar $\left(\mathrm{P}_{3}\right) / /$ Paleontological Journal. Vol.38. No.6. P.680-686.

Lissovsky A.A., Ivanova N.V. \& Borisenko A.V. 2007. Molecular phylogenetics and taxonomy of the subgenus pika (Ochotona, Lagomorpha) // Journal of Mammalogy. Vol.88. No.5. P.1195-1204.

Lissovsky A.A. \& Pavlinov I.Ya. 2008. [Toward exploration of morphological disparity of measurable traits of mammalian skull. 2. Scalar and vector parameters of the forms of group variation] // Zhurnal Obshchei Biologii. Vol.69. No.6. P.344-354 [in Russian, with English summary].
Lissovsky A.A., Yatsentyuk S.P. \& Ge D. 2016. Phylogeny and taxonomic reassessment of pikas Ochotona pallasii and O. argentata (Mammalia, Lagomorpha) // Zoologica Scripta. Vol.45. No.6. P.583-594.

Polly P.D. 2001. On morphological clocks and paleophylogeography: towards a timescale for Sorex hybrid zones // Genetica. Vol.112-113. P.339-357.

Rohlf F.J. 2004. tps serie softwares. Available at http// life.bio.sunysb.edu/morph/.

Sen S. 2003. Lagomorpha // Fortelius M., Kappelman J., Sen S. \& Bernor R.L. (eds.). Geology and paleontology of the Miocene Sinap Formation, Turkey. New York: Columbia University Press. P.163-178.

Thorpe B.R. 1976. Biometric analysis of geographic variation and racial affinities // Biological Reviews. Vol.51. No.4. P.407-452.

Yu N., Zheng C., Zhang Y.-P. \& Li W.-H. 2000. Molecular systematics of pikas (genus Ochotona) inferred from mitochondrial DNA sequences // Molecular Phylogenetics and Evolution. Vol.16. No.1. P.85-95.

\section{Appendix 1. List of specimens, analyzed in morphometric study. Sample labels are followed by localities and Museum IDs.}

For abbreviations see Methods

Ochotona alpina

Erinat - Russian Federation, Republic of Khakassia, Tashtypsky District, Erinat river basin.

females: juvenile: S-33073; subadult: S-9401; adult: S-9915, S-33060, S-33074, S-33079.

males: juvenile: S-33066; subadult: S-33068, S-33076; adult: S-33064, S-33065, S-33067, S-33069.

sex unknown: juvenile: S-9909, S-9927, S-9929.

Zsayan - Russian Federation, Krasnoyarsk Krai, Yermakovsky District, Kulumys and Oyskiy ridges. females: juvenile: S-71743, S-71764, S-71777; subadult: S-71682, S-71767, S-71896; adult: S-71819. males: juvenile: S-71768, S-71772, S-71773; subadult: S-71634, S-71770, S-71810; adult: S-71785. Additional sample of adults:

females: S-71603, S-71611, S-71622, S-71624, S-71684, S-71689, S-71690, S-71819, S-71828, S-71908. males: S-71601, S-71636, S-71638, S-71644, S-71664, S-71679, S-71691, S-71696, S-71887, S-71890.

\section{Ochotona hyperborea}

Zeyskiy - Russian Federation, Amur Oblast, Zeysky District., Zeyskiy Nature Reserve.

females: juvenile: S-150644, S-150666, S-150670, S-150672; subadult: S-150638, S-150674; adult: S-150659, S-150660. males: juvenile: S-186422, S-150642; subadult: S-186420, S-186423; adult: S-150669, S-150673.

Barguzin - Russian Federation, Republic of Buryatia, Severo-Baykalsky District, Barguzin Nature Reserve. females: juvenile: S-116196; subadult: S-4612, S-13324; adult: S-4611, S-13323.

males: juvenile: S-4613; adult: S-4610, S-13322.

sex unknown: juvenile: S-13331; adult: S-8751, S-8752, S-13330, S-35461.

Ochotona macrotis

Tianshan - Kyrgyzstan and Kazakhstan, Teskey Ala-Too.

females: juvenile: S-75011; subadult: S-49410; adult: S-49408, S-58825, S-72086.

males: juvenile: S-49409, S-58828; subadult: S-49406; adult: S-57585, S-58826, S-58827.

sex unknown: juvenile: S-41039; subadult: S-41038, S-57586; adult: S-75010.

Ochotona pallasii

Ulagchin - Mongolia, Bayan-Ölgii Province.

females: juvenile: S-183351, S-183352; subadult: S-18334, S-183344, S-183349; adult: S-183347, S-183354. males: subadult: S-183348; adult: S-183343, S-183345. 